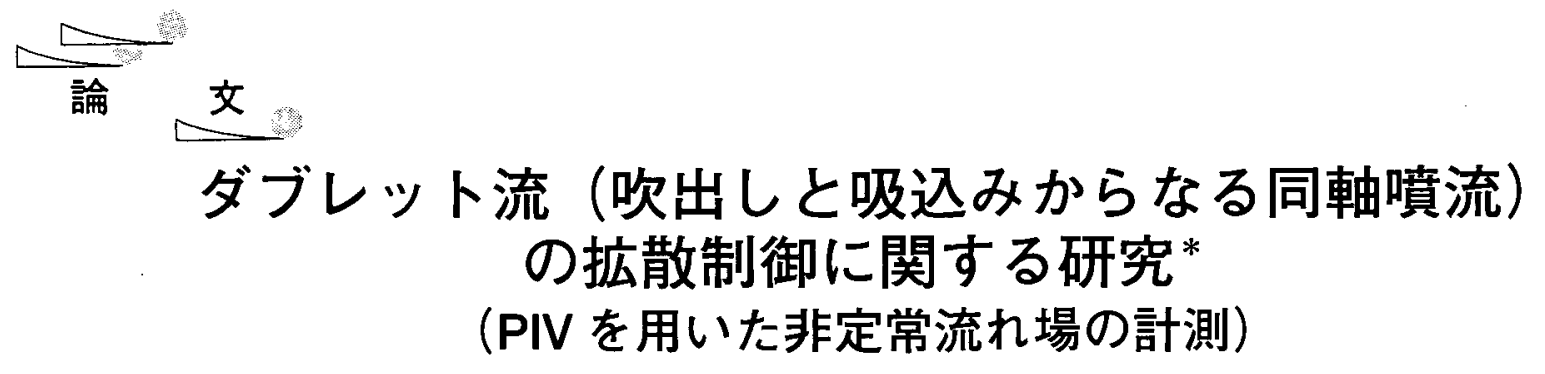

園田 裕和** , 野㠃 米盛敬 ${ }^{* * *}$, 津田 勉*** , 福原 実*****

\title{
Study on Diffusion Control of Doublet Flow Consisting of Injection and Suction Flow (Measurements of Unsteady Flow Field by using PIV)
}

\author{
Hirokazu SONODA, Tsutomu NozAKI, Minoru FuKUHARA, \\ Kei YONEMORI and Minoru TSUdA
}

\begin{abstract}
A doublet flow is the circular free jet added the annular suction flow mounted on the same axis by using a double coaxial pipe. This flow was proposed for the purpose of diffusion control of a circular free jet. The doublet flow was examined experimentally with respect to time mean and unsteady characteristics over the full flow field by using PIV. It was found from the time mean analysis that as the suction velocity increases, the area average value of the fluctuating velocity increases. From the unsteady analysis, it was found that the vortex structures, which have the vorticity that is nearly equal to that of a jet, exist when the suction velocity is high. The vortex structure behaves intermittently, and exists randomly to the radial directions. Thus, the cause of the increase of the fluctuating velocity as described above is clarified by showing the behaviors of these vortex structures.

Key words: Flow control, Particle Image Velocimetry, Unsteady analysis, Vortex structure
\end{abstract}

\section{1. まえがき}

噴流の拡散・混合を制御することは，工学的見地から その必要性が高い ${ }^{1 / 4)}$ ．著者らは，同軸二重円管を用い て円形自由噴流の外側に環状吸込流を設け，せん断層内 の渦構造をこの吸达流により操作し，噴流の掂散・混合 を制御することを提案したゔ.この流れは噴流（吹出し 流）と吸込流が極めて接近して存在することから, 古典 流体力学から引用してダブレット ${ }^{6}$ 流と名付けた。この ような流れ場をこれまでに熱線流速計（CTA）を用い て計測し，以下のような有用な結果を得た。すなわち， 吹出し流速を一定とし，吸达流を増加させることにより， 変動速度が拡散方向に増大寸る，つまり噴流の拡散効果 が得られた。 また，噴流中心軸に対し対称な 2 点におけ

* 原稿受付 1997 年 3 月 18 日

** 正会員 鹿児島大学大学院

*** 正会貝 鹿児島大学工学部

**** 鹿児島大学大学院

***** NEC 九州
る変動速度の相互相関係数を計測し, 非対称な渦放出現 象を見出すことができ，上述した変動速度の増大の要因 を明らかにした。しかしながら，このような流動現象は CTAを用いた点計測により得られた結果であり, 流れ 場全領域についてダブレット流の非定常な拡散現象の解 明を行うには瞬時の多点同時計測が必要である.

近年，トレーサ粒子により可視化された流れ場から， 画像処理技術を用いて速度場の情報を得る方法, つまり

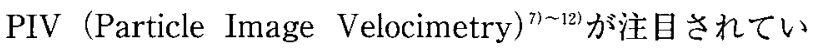
る.この方法は従来の流速計では困難な多点同時計測が 可能であることから，流れ場全領域の非定常計測に対し て極めて有効な手法である。 また流れ場の時間平均特性 についての計測においても，CTA 抢よびレーザドップ ラー流速計（LDA）に代表されるトラバース計測に比 べて，大幅な時間短縮が可能となる．このような利点か ら, PIV は多くの研究機関に拀いて流れ場の計測装置と して用いられている.しかし，従来の PIVシステムで は比較的低速低乱流でなければ計測が困難であることか 
ら，そのほとんどが水流を測定の対象としており，比較 的高速高乱流となる空気流に対しての適用例は少ない。

本報では，PIVのうち濃度パターン相関法を用い，空 気を作動流体としたダブレット流の管出口端近傍の二次 元流れ場の全領域について速度を計測し，吸込流を変化 させることにより，半待方向への拡散の促進現象および 渦構造の放出現象についてそれぞれ時間平均特性および 非定常特性の解析を行った。

記号

$r, z$ : 筒座標

$r_{i}$ : 吹出乙管内半径 $\mathrm{mm}$

$S^{\prime}:$ 变動速度の合成成分 $\left(=\sqrt{{\widetilde{u_{r}^{2}}}^{2}+\widetilde{u}_{r}^{2}}\right) \mathrm{m} / \mathrm{s}$

$t$ : 時間 $\mathrm{sec}$

$\bar{U}_{i}$ : 吹出し流の流路断面積平均值 $\mathrm{m} / \mathrm{s}$

$\bar{U}_{s}$ : 吸込流の流路断面皘平均値 $\mathrm{m} / \mathrm{s}$

$\widetilde{U}_{2}:$ 平均流速の主流方向成分 $\mathrm{m} / \mathrm{s}$

$u$ : 変動速度 $\mathrm{m} / \mathrm{s}$

$\zeta$ : 渦度 $1 / \mathrm{s}$

添字

$=$ : 任意の領域における面皘平均値

$\sim$ : 時間平均值

\section{2．実験装置および方法}

\section{1 可視化装置および方法}

Fig. 1 に可視化装置および画像処理装置の概略を示す. 水平に設置された同軸二重円管の内管を吹出し口，外管 を環状吸込口とした，吹出し管内半径は $23.5 \mathrm{~mm}$, 肉 厚は $1.5 \mathrm{~mm}$, 吸込管内半径は $50 \mathrm{~mm}$ とし, 作動流体 として空気を用いた。ここで吹出し流には助走距離を十 分に取り，管出口端において十分に発達した乱流の速度 分布を有する噴流を用いた，座標は円筒座標系を用い， 管出口端の中心を原点とし，噴流中心軸の方向（主流方 向）に $z$ 軸，半径方向（搪散方向）に $r$ 軸をとる。実 験装置の詳細については前報5を参照いただきたい。

つぎに可視化画像を得る方法について示す。トレーサ 粒子にはタルクパウダ（平均粒子径：10 $\mu \mathrm{m}$ ) を使用し
た．可視化を行う前にトレーサ粒子が測定領域全体に存 在するように，予め流れ場に影響を及ほさない程度の閉 空間内にトレーサ粒子を浮遊させる。 その状態において， 吹出し流中にトレーサ粒子を混入し，测定領域にトレー 开粒子の濃度パターンを形成した，空間的な統計デー夕 量に違いが生じることはやむを得ないが，PIV 解析を行 う際，測定領域全体にわたって，十分なトレーサ粒子数 が存在することを確認している，可視化の手法にはレー ザライトシート (LLS) を使用し，その光源にはダブル パルス Nd:YAGレーザ (出力: $15 \mathrm{~mJ} /$ pulse, ビーム

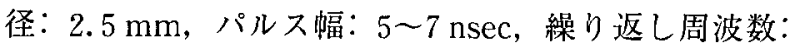
$30 \mathrm{~Hz}$ )を用い, シリンドリカルレンズにより厚さ約 10 $\mathrm{mm}$ (実際，トレーサ粒子の濃度パターンが可視化され る面は厚さ $10 \mathrm{~mm}$ のうちの中心付近の光強度が高く, 薄い領域である) のシート状にして測定断面（r-z断面） に間欠照射した。

第 1 章で述べたと扔り，PIV を用いた計測の殆どが作 動流体として水を用いた低速低乱流の流れを計測対象と したものである.これは一般的に画像入力装置として NTSC 方式の CCD メラを用いるため，そのフレーム レート（1/30 秒）に依存した時間分解能しか得られず, トレーサ粒子の分布パターンの移動速度㧍よび変形速度 が速い場合，分布パターンの 2 時刻間における対応付け が困難または不可能となるためである。 そこで今回，作 動流体として空気を用いた高速高乱流の流れを計測する ために以下のような手法を用いた。すなわち，LLSの 照射タイミングを CCD カメラから出力される映像信号 に同期させ，フレーム画像を構成する2つのフィールド 画像の境界付近，つまり第1フィールドの後半部分と第 2 フィールドの前半部分にそれぞれLLSを照射した。

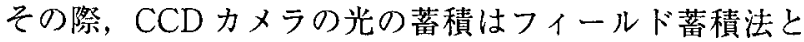
し，同一フレーム上に 2 時刻の濃度分布パターンを画像 化した。 上述の手法によりフレームレートに依存しない 短い時間間隔の 2 時刻の画像が得られる。また光源とし てパルスレーザを用いた場合, 連続光レーザを $\mathrm{AOM}$ (音 響光学セル）によりパルス化する場合と比べて高い出力

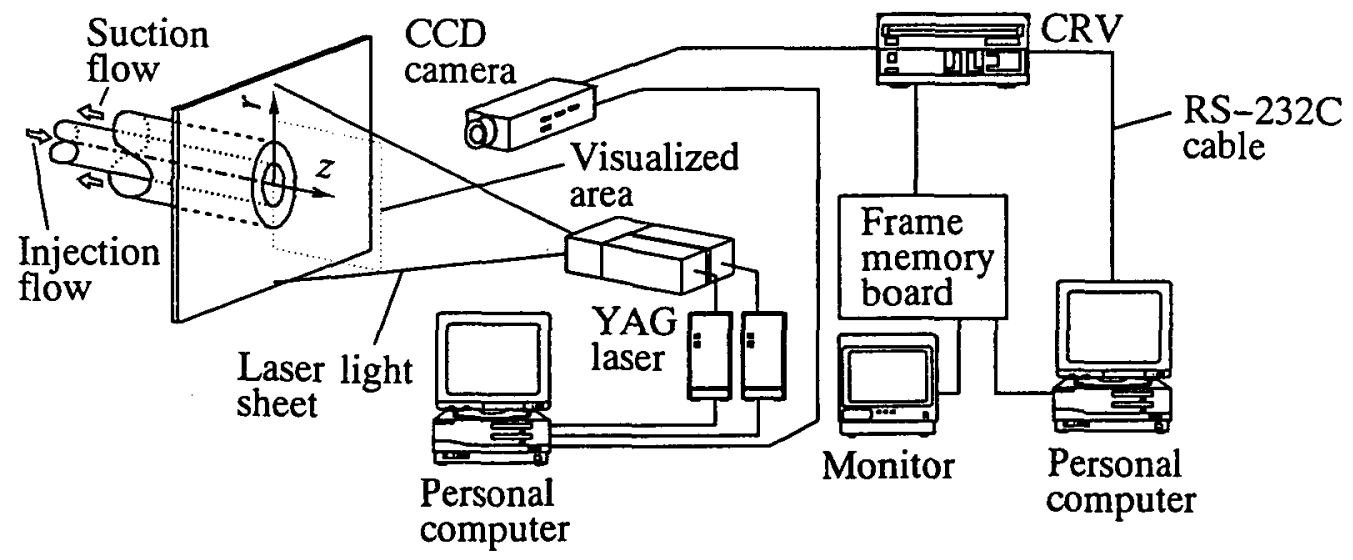

Fig.1 Schematics of visualization system and image processing system 
が得られ，しかもパルス幅が $5 \sim 7 \mathrm{nsec}$ と短いことから， 鮮明でしかもトレーサ粒子が流跡線とならず殆ど静止し た状態の画像を得ることができた。本装置ではLLSの 照射間隔を任意の時刻に設定でき，測定の対象とする流 れ場の速度抢よび画像の空間分解能を考虑し，本実験で は $0.7 \mathrm{msec}$ と設定した。この LLSの照射は各フレーム ごとに連続的に行われる。このようにして得られた CCD カメラの出力画像は CRV (光ディスク) に転送, 記録 された。

\section{2 画像処理装置および方法}

上述の手順で得られた面像をフレームメモリーボード により $512 \times 480$ ピクセルで 256 階調の画像として A/D 変換し,さらに第 1 フィールドと第 2 フィールドを分離 することにより，解析に使用する 2 時刻の入力画像（前 半の画像を $\mathrm{F} 1$, 後半の画像を $\mathrm{F} 2$ と呼ぶ) を作成した。 画像の空間分解能は約 $0.25 \mathrm{~mm} /$ ピクセルである。こ のようにして得られた 2 時刻の画像に対し濃度相関係数 の計算を行い速度べクトルを算出した．解析手順につい て以下に示す．まず，F1に対し速度べクトルの始点と

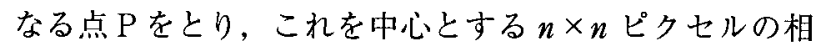
関マトリックスを定義する. 次に F 2 に 1 の点 $\mathrm{P}$ と同 じ位置を中心とする $m \times m$ ピクセルの捜査マトリック スを設定し，相関マトリックスをその中心 $\mathrm{P}$ が捜査マ トリックス内に存在するように平行に逐次移動させ, 各 ピクセルごとに濃度相関係数 $\mathrm{Cr}$ を,

$$
C r=\frac{\sum_{i=1}^{n^{2}} f_{i} g_{i}-\left(1 / n^{2}\right) \sum_{i=1}^{n^{2}} f_{i} \sum_{i=1}^{n^{2}} g_{i}}{\left\{\sum_{i=1}^{n^{2}} f_{i}^{2}-\left(1 / n^{2}\right)\left(\sum_{i=1}^{n^{2}} f_{i}\right)^{2}\right\}^{1 / 2}\left\{\sum_{i=1}^{n^{2}} g_{i}^{2}-\left(1 / n^{2}\right)\left(\sum_{i=1}^{n^{2}} g_{i}\right)^{2}\right\}^{1 / 2}}
$$

により計算する。ここで，f扔よび $g$ は F 1 および $\mathrm{F} 2$ にそれぞれ定義したマトリックス内に扔ける各ピクセル での画像濃度を示す。得られた濃度相関係数分布から ピーク位置を検出し，その点を点 $\mathrm{P}$ を始点とする速度 ベクトルの終点とした.ここで, 速度計測の精度の向上 を図るため, ピーク位置周囲の濃度相関係数分布に対し 統計的処理 ${ }^{13)}$ を施し, 1 ピクセル以下の移動量を算出した. 今回測定領域全体に扔いて濃度相関倸数 $C r$ がある値 (ここでは便宜上 0.55 とした）以下のベクトルおよび平 均流速から $\pm 3 \sigma$ (ここで $\sigma$ は標準偏差）以上離れた值 を示すべクトルを過誤ベクトルと判定した。本報におい て相関マトリックスのサイズは，噴流中心軸上，せん断 層付近および噴流外部の流れ場の代表的な数力所を抽出 し PIV 解析を行った結果, $n \geqq 41$ ピクセルにおいて速 度べクトルの平均值が一定となり, また高い濃度相関係 数 $\mathrm{Cr}$ の值が得られたため $n=41$ ピクセルと設定した。 また捜査マトリックスのサイズは $m=51$ ピクセルと設 定した。また，時間平均特性については 1,000 フレーム
の平均量として算出した。本実験での一連のPIVによ る解析には, 市販の画像処理流速計測システムCurrent PIV Ver.1.15 [日本カノマックス侏］を用いた。

\section{3 実験条件}

流速は，吹出し流速 $\bar{U}_{i}$ を $2.0 \mathrm{~m} / \mathrm{s}$ に一定とし，吸込 流速 $\bar{U}_{s}$ との流速比 $\bar{U}_{s} / \bar{U}_{i}$ を $0,0.37,0.55,0.65$, $0.74 ， 0.79 ， 0.86 ， 0.92 ， 0.96$ 抢よび 1.0 の 10 通りに

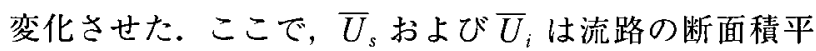
均值を示す。測定領域は管出口端近傍に限定しているの で, $z / r_{i} \leqq 5.0$ の主流方向の範囲とした。ここで, $r_{i}$ は 吹出し管内半径である.ただし, $0<z / r_{i}<0.5$ の範用で は，LLSが吹出し管および吸达管の影響により反射し， 解析上過誤ベクトルが多く発生するため，この領域の結 果は表示しない。

\section{3. 実験結果および考察}

\subsection{PIV の測定精度}

まず，PIVを用いて得られた噴流中心軸上における平 均流速および変動速度の分布について, CTA を用いて 得られた結果との比較検討を行い，PIV の測定精度につ いて考察する. Fig. 2 に示すように, 流速比 $\bar{U}_{s} / \bar{U}_{i}$ は 0 および 0.92 の場合を例にとる. 図中の横軸は $z / r_{i}$ を， 縦軸は平均流速の主流方向成分 $\widetilde{U}_{z}$ および変動速度の主 流方向と搪散方向の合成成分 $S^{\prime}\left(=\sqrt{\widetilde{u}_{z}^{2}+\widetilde{u}_{r}^{2}}\right)$ をそれぞ れ $\bar{U}_{i}$ で無次元化した值を示す。 $\bar{U}_{s} / \bar{U}_{i}=0$ すなわち自 由噴流の場合について比較する。 $\widetilde{U}_{z}$ の両者はほほ一致 しており，S’はPIVによる值のほうがCTAによる值 に比べ若干高い. 流速比が大きい $\bar{U}_{s} / \bar{U}_{i}=0.92$ の場合 には、 $\widetilde{U}_{z}$ および $S$ のいずれも雨者に多少差異が生じ ている.このように流速比が大きくなると, 前報〉で示 したように円周方向への三次元性が強くなり, 今回用い た二次元 PIV 計測では解析上䛊差が生じやすくなる. また，瞬時に逆流を伴う流れ場が存在することから，

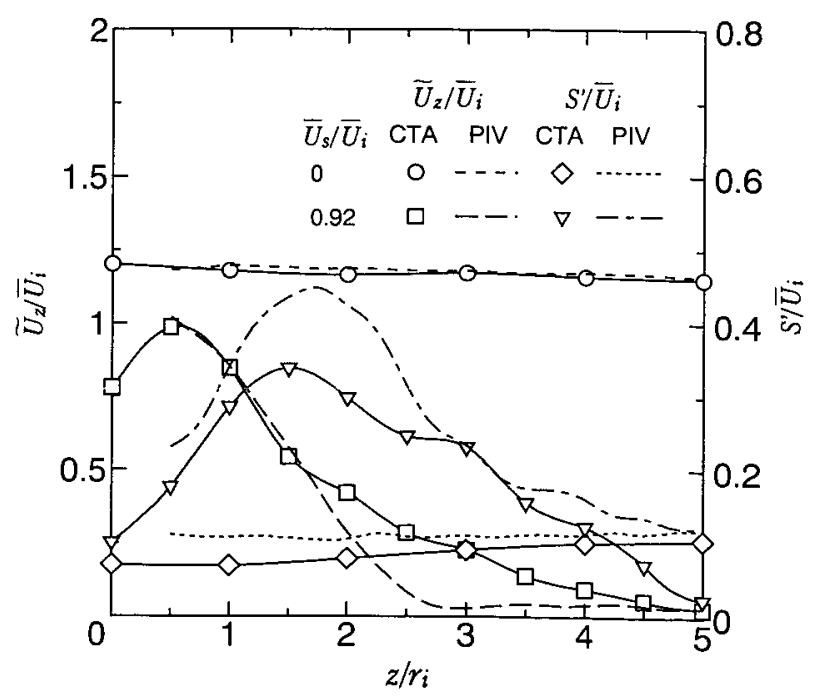

Fig.2 Comparison between the results of PIV and those of $\operatorname{CTA}\left(r / r_{i}=0\right)$ 
CTA 計測においても誤差が生じやすくなるため, 誤差 の評価は容易でない。このような状況において，本実験 では水流に比べて計測が困難な空気流を測定対象とする 中, 本論文の議論の範囲内では PIV の測定精度は十分 であると考える。

\section{2 時間平均特性}

上述した測定精度を持つPIVを用いて得られた時間 平均特性の解析結果を示す。まず, 吹出し流と吸込流の 関係を明らかにするため，平均流速の主流方向成分 $\widetilde{U}_{z}$ について調べた， $\bar{U}_{i}$ で無次元化した $\widetilde{U}_{2}$ の等高線図を， 例として $\bar{U}_{s} / \bar{U}_{i}=0,0.65$ および 0.92 についてれぞ れ Fig. 3(a) (c)に示す.ここで, 2.3 節で述べたように, 主流方向の測定領域は $0.5 \leqq z / r_{i} \leqq 5.0$ とした。 また， 拡散方向の測定領域は流れの軸対称性を考慮し, 鉛直下 方向のみ $0 \leqq r / r_{i} \leqq 3.0$ とした. $\vec{U}_{s} / \bar{U}_{i}=0$ すなわち自由 噴流の場合, せん断層の $r / r_{i}=1.0$ 付近に速度勾配の大 きい領域が存在し，下流へ行くにつれその勾配は若干緩 やかになる. $\bar{U}_{s} / \bar{U}_{i}=0.65$ の場合には吸込管端のごく 近傍に吸込流の存在が確認でき, 自由噴流の場合と比べ て吹出し流の速度勾配は緩やかとなる. さらに流速比が 大きい $\bar{U}_{s} / \bar{U}_{i}=0.92$ の場合には, 吸込流がさらに增加 する様子が観察でき，その影響を受けた吹出し流は下流 まで到達できず, 速度勾配の大きい領域は管端近傍に存 在することがわかる.

つぎに拡散の程度を明らかにするため, 変動速度の主 流方向と拡散方向の合成成分 $S^{\prime}\left(=\sqrt{\widetilde{u_{z}^{2}+\widetilde{u}_{r}^{2}}}\right)$ について
調べた. $\bar{U}_{i}$ で無次元化した $S^{\prime}$ の等高線図を Fig. 4 に示 す. Fig. 4(a)〜(c)は Fig. 3 と同じ流速比の条件である.

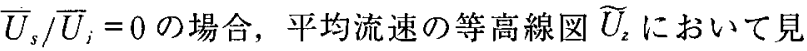
られた速度勾配の大きい領域すなわち $r / r_{i}=1.0$ 付近に, 変動速度の高い領域が存在する. $\bar{U}_{s} / \bar{U}_{i}=0.65$ の場合 に抢いても，速度勾配の大きい領域に変動速度の大きい 領域が存在する.ささらに流速比の大きい $\bar{U}_{s} / \bar{U}_{i}=0.92$ の場合にも，速度勾配の大きい領域すなわち管端近傍に, 変動速度の高い領域が存在する.よって，いずれの流速 比においても速度勾配の大きい領域と変動速度の高い領 域はほ活対応している。

これらの変動速度の值を流速比の影響について定量的 に評価するため，任意の領域における変動速度 $S^{\prime}$ の面 積平均值として,

$$
\overline{\overline{S^{\prime}}}=\frac{\int S^{\prime} \mathrm{d} A}{\int \mathrm{d} A}
$$

が定義される.ここで， $A$ は任意の領域の面積を示して いる. 本実験では $S^{\prime} / \bar{U}_{i} \geqq 0.1$ となる領域において解析 を行うことにした，各流速比の計算結果を Fig. 5 に示す. 図中の横軸は流速比 $\bar{U}_{s} / \bar{U}_{i}$ を, 縦軸は変動速度の面積 平均値 $\overline{\bar{S}}$ を $\bar{U}_{i}$ で無次元化した值を示す. $\bar{U}_{s} / \bar{U}_{i}<0.65$ の範囲では，吸込流が増加するにつれ変動速度の面積平 均値は緩やかに增加するが, $\bar{U}_{s} / \widehat{U}_{i} \geqq 0.65$ ではその值 は急激に增大し, $\bar{U}_{\mathrm{s}} / \bar{U}_{i}=0.86$ に扔いて最大值をとる.

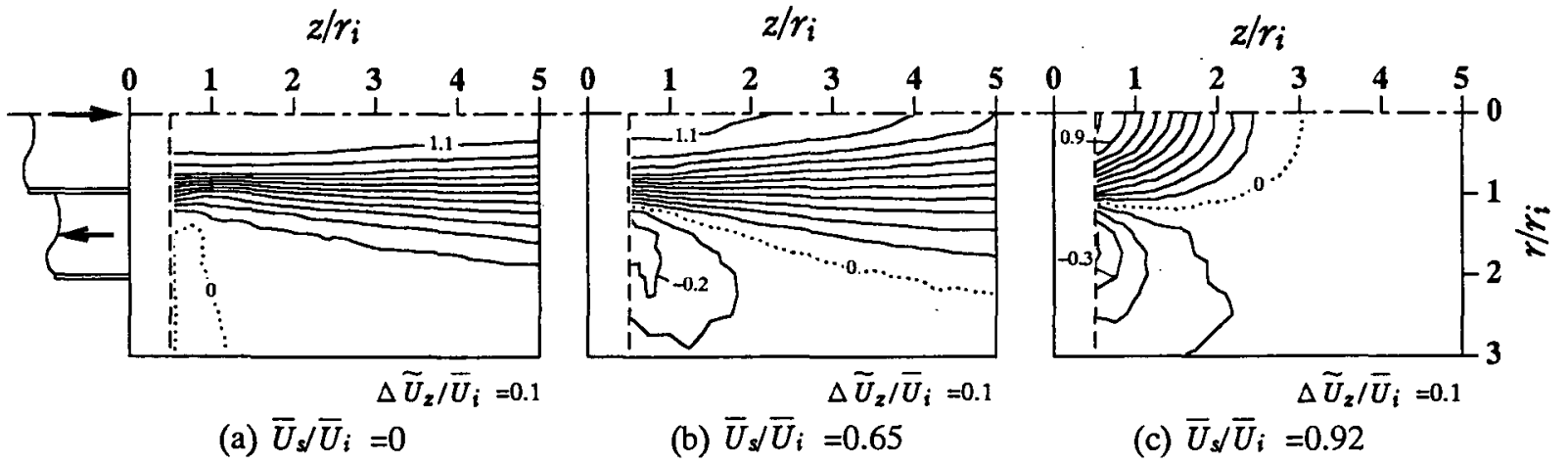

Fig.3 Contour maps of time mean axial velocity

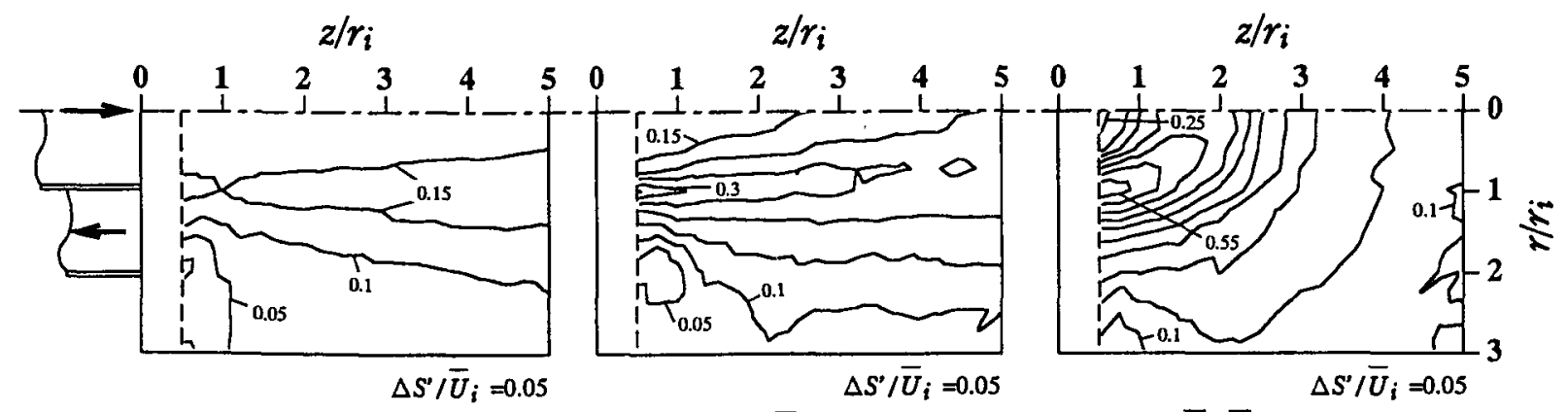

(a) $\bar{U}_{s} / \bar{U}_{i}=0$

(b) $\bar{U}_{s} / \bar{U}_{i}=0.65$

(c) $\bar{U}_{s} / \bar{U}_{i}=0.92$

Fig.4 Contour maps of fluctuating velocity 


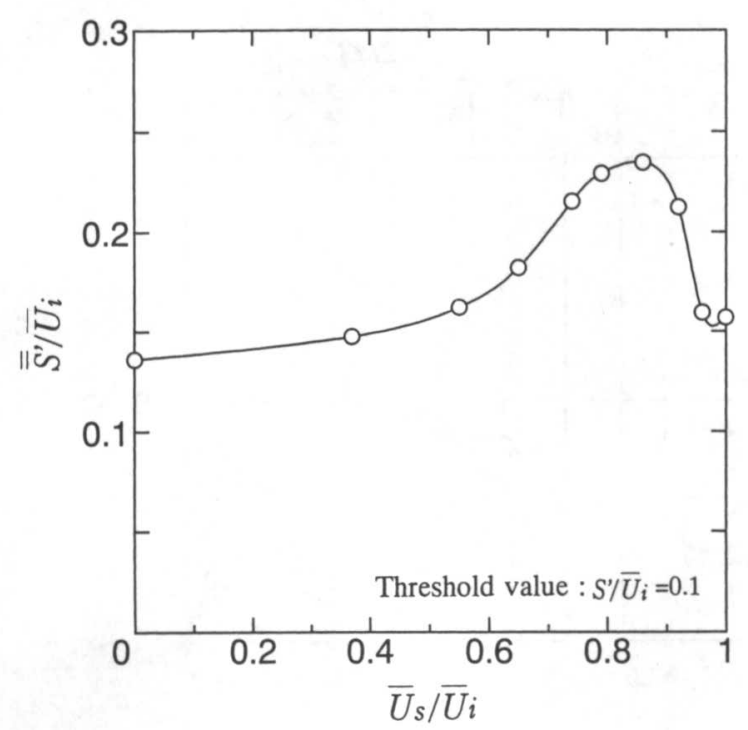

Fig.5 Area average values of fluctuating velocity

その值は $\bar{U}_{s} / \bar{U}_{i}=0$ の場合に比べ約 1.7 倍も高くなる. さらに $\bar{U}_{s} / \bar{U}_{i} \geqq 0.96$ では, 吸込流が強すぎるため $\overline{\bar{S}} / \bar{U}_{i}$ は極めて低い值を示す.このように吸込流が増加
するにつれ変動速度が増大し，拡散が促進されているこ とがわかる.

\section{3 非定常特性}

前報らに扔いて熱線流速計を用いて洞構造の非定常性 を示したが，これは点情報から得られた結果である。ま た，可視化画像で得られた空間的な渦構造の挙動から定 量的な情報を得ることはできない。これらの問題を解決 する手法が PIV 計測であり, 以下にその非定常特性の 解析結果を示す．まず，各流速比における可視化画像と その画像に基づく瞬時の渦度分布の解析結果をそれぞれ Fig. 6 抒よびFig. 7 に示す. 図中(a)〜(c)はそれぞれ $\bar{U}_{s} / \bar{U}_{i}=0,0.65$ および 0.92 の条件である. 図中の渦 度らは $\bar{U}_{i} / r_{i}$ で無次元化してある。噴流中心軸に対する 非対称性を調べるため, 拡散方向の測定領域は鉛直上下 方向に $0 \leqq r / r_{i} \leqq 2.5$ とした. Fig. 6 に示す可視化画像か ら，流速比が大きくなると吹出し流が連続的に放出され ず，しかも対称性を失う様子が観察できる. Fig. 7 から わかるように, $\bar{U}_{s} / \bar{U}_{i}=0$ の場合, $r / r_{i}=1.0$ 付近にお いて渦度の高い領域が下流まで連続して存在し, 噴流中 心軸に対する対称性も保たれている. $\bar{U}_{s} / \bar{U}_{i}=0.65$ の

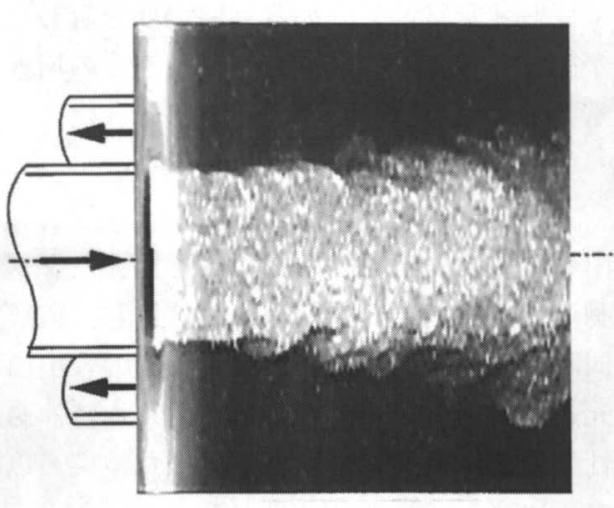

(a) $\bar{U}_{s} / \bar{U}_{i}=0$

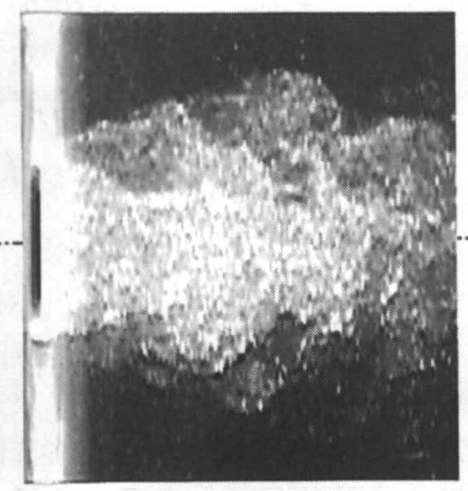

(b) $\bar{U}_{s} / \bar{U}_{i}=0.65$

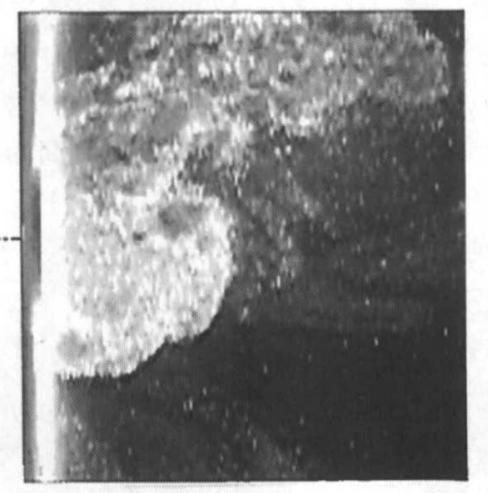

(c) $\bar{U}_{s} / \bar{U}_{i}=0.92$

Fig.6 Flow visualization photographs

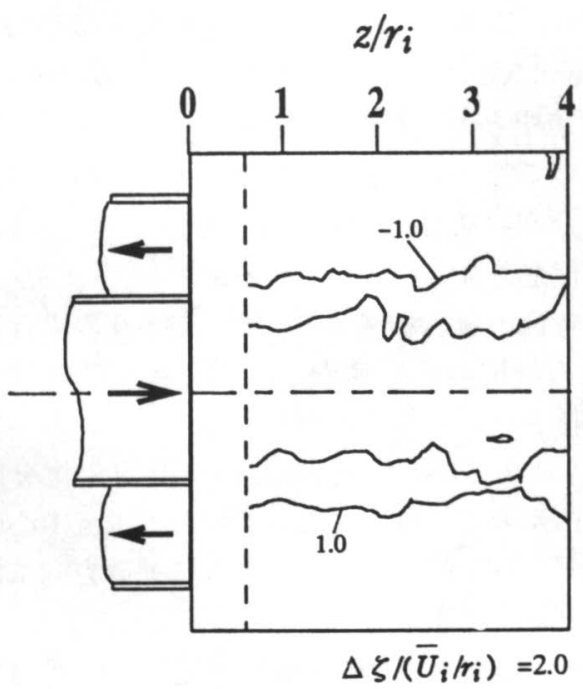

(a) $\bar{U}_{s} / \bar{U}_{i}=0$ $z / r_{i}$

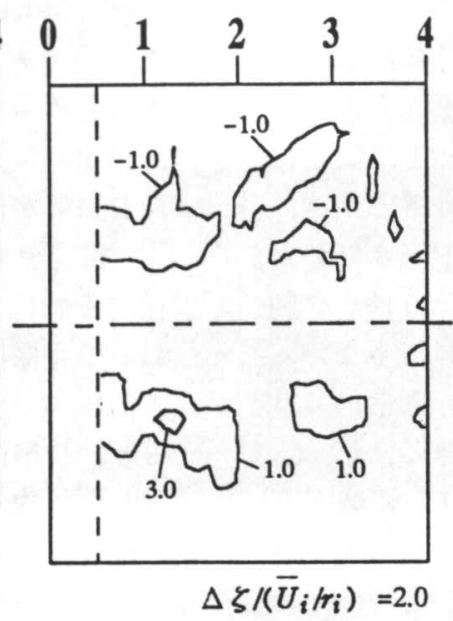

(b) $\bar{U}_{s} / \bar{U}_{i}=0.65$ $z / r_{i}$

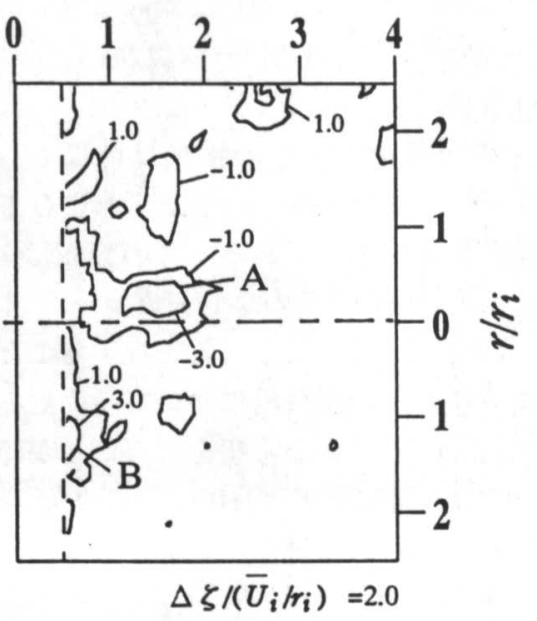

(c) $\bar{U}_{s} / \bar{U}_{i}=0.92$

Fig.7 Contour maps of instantaneous vorticity 


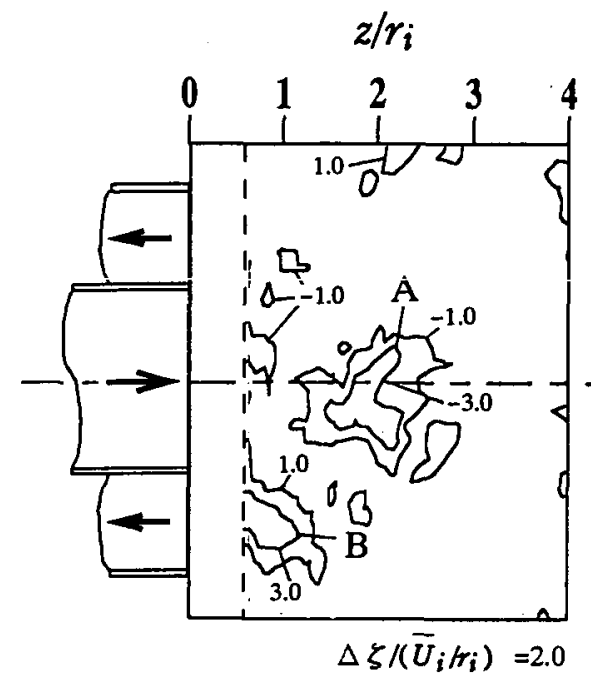

(a) $t_{1}=t_{0}+1 / 30 \mathrm{sec}$

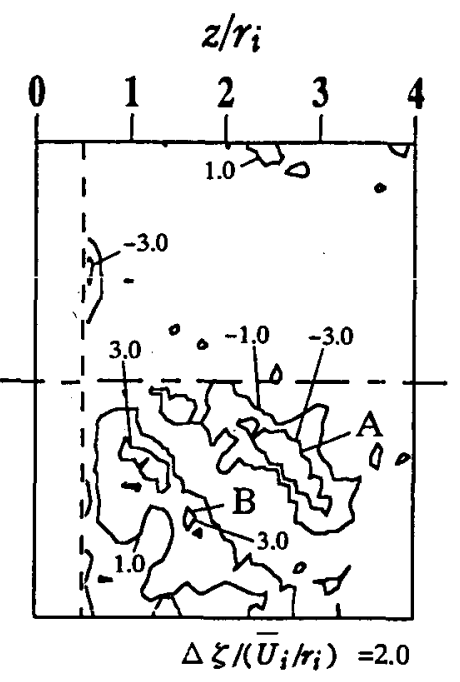

(b) $t_{2}=t_{0}+2 / 30 \mathrm{sec}$

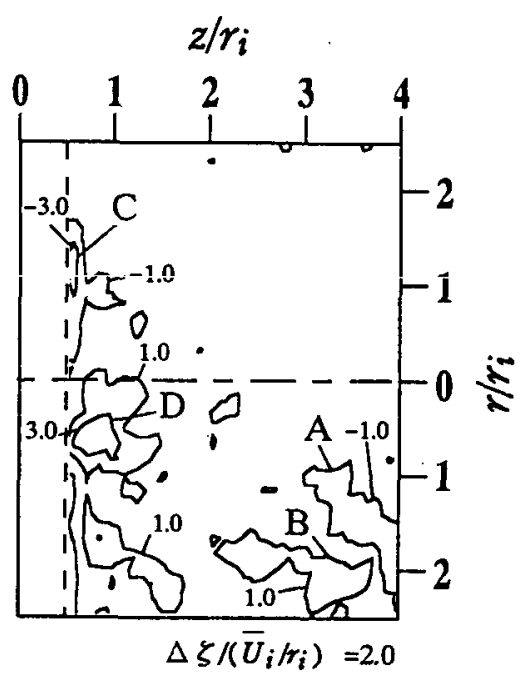

(c) $t_{3}=t_{0}+3 / 30 \mathrm{sec}$

Fig.8 Time sequence of instantaneous vorticity $\left(\bar{U}_{s} / \bar{U}_{i}=0.92\right)$

場合， $z / r_{i}=2.0$ 付近から下流まで自由噴流とは異なり 若干連続性扔よび刘称性が失われてくる. $\bar{U}_{s} / \bar{U}_{i}=0.92$ の場合，その現象はさらに顕著となるが, $\bar{U}_{s} / \bar{U}_{i}=0$ と 同程度の高い渦度を有する領域が存在することがわかる.

$\bar{U}_{s} / \bar{U}_{i}=0.92$ の場合の非定常解析において観察され た渦構造の挙動を調べるため, 時間的に変化した瞬時の 渦度分布を Fig. 8 に示す.ここで, Fig. 8(a)〜(c)は Fig. 7 (c)を起点とした渦構造の挙動を $1 / 30$ 秒間隔で示してい る. Fig.7(c)に示した $t=t_{0} \sec に$ 扔いて管出口端で既 に非対称となった渦構造（図中 A およびB）が観察で きる. 次の時間ステップの $t_{1}=t_{0}+1 / 30 \mathrm{sec}$ および $t_{2}=$ $t_{0}+2 / 30 \mathrm{sec}$ では，高い渦度を保持しながら拡散方向に 放出される渦構造の様子が観察できる.さらに $t_{3}=$ $t_{0}+3 / 30 \mathrm{sec}$ では，管出口端付近に次に放出される非对 称な渦構造（図中 C 抄よびD）が観察される.

さらに，主流方向を $z / r_{i}=2.0$ の位置に固定し，時間 的かつ空間的（掂散方向）な渦の挙動を調べた。ここで は, 計測時間 3 秒（フレーム数 90 個分）における結果 を Fig. 9 に示す.ここで, Fig. 9 (a)〜(c)は Fig. 7 と同じ 流速比の条件で，図中の横軸は時間 $t$ [sec]を，縦軸は $r / r_{i}$ を示す．また渦度らは Fig. 7 および Fig. 8 と同様， $\bar{U}_{i} / r_{i}$ で無次元化してある。この分布は，Fig. 8 でわか るようにCCDカメラのフレームレート (1/30 秒) の制 䄪上，時間的に連続的な現象を捉えることはできない。 このように高速の流れ場において時間刻みが離散的では あるが，以下のような考察を行うことができる。 $\bar{U}_{s} / \bar{U}_{i}$ $=0$ の場合, 常に $r / r_{i}=1.0$ 付近に渦度の高い領域が存 在し，噴流中心軸に対する対称性も保たれ，定常的な流 れ場であることがわかる. $\bar{U}_{s} / \bar{U}_{i}=0.65$ の場合，その 分布は自由噴流と比較して若干間久的となり，噴流中心 軸に対する対称性が失われてくる.変動速度の高い $\bar{U}_{s} / \bar{U}_{i}=0.92$ の場合, $\bar{U}_{s} / \bar{U}_{i}=0.65$ の場合よりもさら
に間欠的でしかも拡散方向にランダムに存在することか ら，非定常性の強い渦放出現象を示す．このように吸込 流の増加に伴い非定常性を強める高い渦度を有した渦構 造の挙動が観察できた，以上より，変動速度の増大の要 因を非定常解析から明らかにすることができた。

\section{4. 結論}

円形自由噴流の周囲に環状の吸込流を加えたダブレッ 卜流（作動流体：空気）の拡散現象に着目し，PIVを用 いて多点同時計測を行った．ダブレット流の管出口端近 傍の二次元速度場の全領域において時間平均特性および 非定常特性に及ぼす流速比の影響を調べた結果, 以下の 結論を得た。

（1）いずれの流速比においても，平均流速の速度勾配の 大きい領域と変動速度の高い領域はほぼ対応している。

（2）それぞれの流速比における変動速度の面積平均值は $\bar{U}_{s} / \bar{U}_{i} \geqq 0.65$ において急激に增加し, $\bar{U}_{s} / \bar{U}_{i}=0.86$ に おいて最大值をとり， $\bar{U}_{s} / \bar{U}_{i} \geqq 0.96$ では吸込流が強す ぎるため極めて低い值を示す。したがって，拡散制御の 観点から, 今回の条件において $\bar{U}_{s} / \bar{U}_{i}=0.86$ の場合に 最も拡散が促進されることがわかる.

(3) 非定常特性の解析結果から， $\bar{U}_{s} / \bar{U}_{i}=0$ の場合に存 在する瞬時の渦度の高い値が, $\bar{U}_{s} / \bar{U}_{i}=0.92$ の場合に おいても保持されていることがわかる.

(4) $\bar{U}_{s} / \bar{U}_{i}=0.92$ の場合の渦構造の時間的変化を調べ ると，管出口端のごく近傍においてすでに噴流中心軸に 対し非対称となり，時間の経過とともに拡散方向に放出 される様子が観察できる。

(5) 主流方向を $z / r_{i}=2.0$ の位置に固定し, 時間的かつ 空間的（拡散方向）な渦の挙動を調べると, 変動速度の 高い $\bar{U}_{s} / \bar{U}_{i}=0.92$ の場合, その分布は問欠的となりし かも拡散方向にランダムに存在することから, 非定常性 


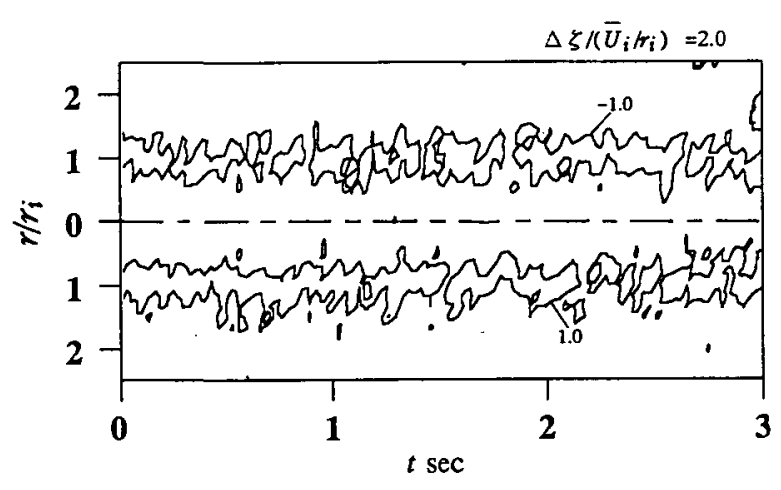

(a) $\bar{U}_{s} \bar{U}_{i}=0$

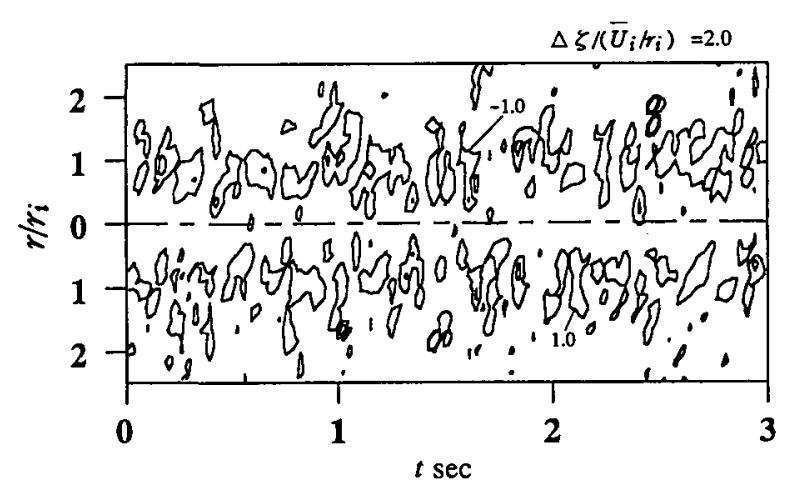

(b) $\bar{U}_{s} / \bar{U}_{i}=0.65$

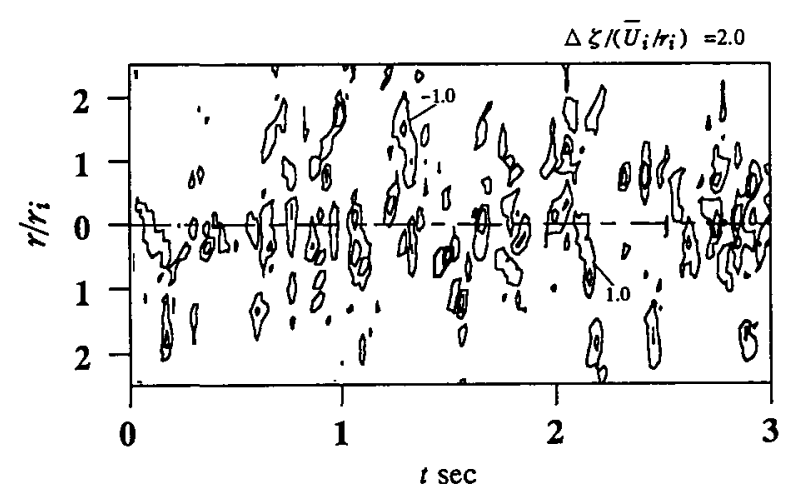

(c) $\bar{U}_{s} / \bar{U}_{i}=0.92$

Fig. 9 Time sequence of instantaneous vorticity distributions at $z / r_{i}=2.0$

の強い渦放出現象を示すことができる.

よって，上述した非定常解析において観察される渦構 造の挙動から, 変動速度の増大の要因を明らかにするこ とができた．このように，PIVを用いた速度場の全領域 について時間平均解析㧍よび非定常解析を行い，ダブ レット流の非定常な拡散現象の解明に対し有用な知見を
得ることができ，PIV 計測が極めて有効であることを確 認することができた。今後，吹出し管と吸込管の管径比， レイノルズ数および吹出し流の初期条件（出口速度分布 および初期変動速度）等の影響について PIV 解析を行 う予定である.

終わりに臨み，PIVを用いた計測を行うにあたり新日 本製鐵(秼津田宜久氏より貴重なご助言を，また日本力ノ マックス秼より YAGレーザの貸与を賜った。記して謝 意を表す。また，本実験に協力をいただいた本学部 4 年 生の上田和成抢よび野口寛樹の両氏に謝意を表す。

\section{参考文献}

1) Crow. S. C. and Champagne, F. H.: Orderly structure in jet turbulence, Jour. of Fluid Mechanics. 48 (1971), 547-591.

2) Hussain, F. and Husain, H. S. : Elliptic jets. Part 1. Characteristics of unexcited and excited jets, Jour. of Fluid Mechanics, 208 (1989), 257-320.

3 ）豊田国昭，白浜芳朗，小谷幸慈：渦構造の操作による非円形 噴流の制御に関する研究，日本機械学会諭文集 (B編)，58545 (1992), 7-13.

4 ）栗間䛨二, 宮本政英, 笠木伸英, 平田賢：軸対称噴流の渦輪 挙動に対する周期的じょう乱の効果, 日本機械学会論文集 (B 編), 60-574 (1994), 2007-2013.

5 ）野㟝勉, 園田裕和, 李輝, 福原稔, 南田純也：ダブレット流 (吹出しと吸込みからなる同軸噴流) の掂散制御に関する研究， 日本機械学会論文集（B 編）, 62-598（1996）, 2208-2214.

6 ）例えば, Milne-Thomason, L.M.: Theoretical Hydrodynamics, Macmillan \& Co LTD (1962), 149-150.

7) Adamczyk, A. A. and Rimai, L.: Reconstruction of a 3dimensional flow field from orthogonal views of seed track video images, Experiments in Fluids, 6 (1988), 380-386.

8) Hesselink, L. : Digital image processing in flow visualization, Annual Reviews of Fluid Mechanics. 20 (1988), 421-485.

9 ）小林敏雄, 佐賀徹雄, 瀬川茂樹, 神田宏: 二次元流れ場の実 時間ディジタル画像計測システムの開発，日本機械学会論文 集 (B 編) ,55-509 (1989), 107-115.

10) Willert, C. E. and Gharib, M.: Digital particle image velocimetry. Experiments in Fluids, 10 (1991), 181-193.

11) Adrian, R. J.: Particle-imaging techniques for experimental fluid mechanics, Annual Reviews of Fluid Mechanics, 23 (1991), 261-304.

12）佐田豊, 佐藤一穂, 笠木伸英, 高村則之： 3 次元画像処理流 速計による乱流気流計測，日本機械学会論文集 (B 編)，60-571 (1994), 865-871.

13）津田宜久, 小関常雄, 小林敏雄, 佐賀徹雄：濃度相関法によ る速度計測システムの開発, 第 7 回流れの計測大阪シンポジ ウム, 11-15 (1993), 83-87. 